\title{
Gluten-free and casein-free diets in the treatment of autism
}

\author{
Andreas Reissmann, Joachim Hauser, Ewelina Makulska-Gertruda, Loredana Tomsa, \\ and Klaus W. Lange
}

Department of Experimental Psychology, University of Regensburg, 93040 Regensburg, Germany

Corresponding author: Klaus $\mathrm{W}$. Lange, $\mathrm{PhD}$, Professor, Department of Experimental Psychology, University of Regensburg, Regensburg 93040, Germany

Submission date: February 28, 2014; Acceptance date: July 29, 2014; Publication date: August 5,2014

\begin{abstract}
Background: Autism is a complex psychiatric disorder characterized by three core symptoms, i.e. impairments in social interaction, restricted patterns of behavior and impairments in communication. In the framework of the "opioid excess theory", the disorder symptoms are compared to the behavioral effects of opiates. Based on this, a possible nutritional basis of autism has been proposed, hypothesizing that certain food proteins such as gluten and casein can be transformed to opioid peptides during digestion. These peptides might eventually be able to enter the blood stream and act upon the central nervous system. As a consequence, a diet low in such proteins has been hypothesized to ameliorate the behavioral symptoms of autistic children.
\end{abstract}

Objective: The scope of this review was to analyze the effects of gluten-free and casein-free (GFCF) diets on children with autism, as well as to provide information concerning additional aspects related to the GFCF diet in autism.

Methods: A literature search was conducted including scientific publications up until December 2013. Search results were screened for any kind of GFCF dietary intervention as well as surveys dealing with GFCF as a treatment for autism.

Results: A review of survey data shows that up to $25 \%$ of parents of affected children report on current use of a GFCF diet. The majority of identified studies evaluating GFCF diet outcomes failed to meet basic methodological standards of interventional science. Comparison of study results did not show any clear-cut results, with a substantial proportion of studies failing to show any positive dietary effect. The results of more sophisticated trials were far from equivocal and the studies differed by many methodological aspects. Some variables such as information source and trial duration seemed to affect outcome. 
Conclusions: Evidence for the effectiveness of the GFCF diet in the treatment of autism is sparse. Rigorous scientific evaluations partly failed to confirm therapeutic effects of the GFCF diet. These and other negative results related to the opioid excess theory weaken the underlying rationale for GFCF diet use. Nevertheless, more sophisticated investigations should be conducted in order to identify possible benefits and harms of such a dietary approach.

Key words: gluten-free and casein-free diet, opioid excess theory, autism, autistic spectrum disorder, therapeutic effects, evidence base, prevalence of use

\section{Autism and the Quest for Etiology: A Case for Nutrition?}

Autism is a complex psychiatric disorder of childhood and adolescence [1]. According to the Diagnostic and Statistical Manual of Mental Disorders (DSM-5; [2]) autism is characterized by three core symptoms, i.e. impairments in social interaction, restricted patterns of behavior and impairments in communication, The disorder has been shown to occur in approximately $0.2 \%$ of child and adolescent populations. Prevalence estimates seem to have risen over the last two decades [3]. Prevalence estimates for autistic disorder before 1987 did not exceed $0.07 \%$, while, for reasons as yet unknown, all studies published since 2000 have consistently shown higher rates (range 0.07 to $0.4 \%$ ). While the increase in prevalence might be attributed to a concomitant rise in the incidence of the disorder, other factors such as changes in the concepts and diagnostic criteria as well as a growing awareness within Western societies have been suggested as alternative explanations [3]. Risk-inducing environmental agents and the potential role of nutrition have been discussed in the context of a gene-environment interaction [see 4]. From this point of view, an unbalanced diet might be able to induce biological vulnerability by itself or an otherwise balanced diet might disturb the organism's homeostasis in the case of metabolic insufficiency [4]. The question of whether or not such an explanatory model can be put forward is a matter of ongoing research and debate [5].

Etiological accounts of autism emphasize biological factors associated with organism (genes) and environment (e.g. exposure to neurotoxic agents) and seek to relate the influences of these factors to biomarkers of brain and organismic function [1, 6, 7]. Potential biomarkers of autism include structural brain abnormalities (e.g. increased brain volumes, especially in frontal cortex, cerebellum and amygdala), functional brain abnormalities (e.g. disconnectivity of cortical structures with more asynchrony in activity, abnormal levels of neurotransmitters and neuropeptides), systemic indicators related to metabolism (e.g. indicators of mitochondrial dysfunction, abnormal urinary excretion of organic acids) and indicators of an increased dysregulation of immune functions [6]. These findings are complemented by the confirmation of the disorder's association with genes related to cell structure and function, neuronal development, synaptic formation and with genes involved in neurotransmission [6]. There are also indications for a heightened prevalence of autism following exposure to certain environmental agents such as pesticides and solvents, which could affect brain development [6]. The search for biomarkers of autism has led to inconclusive results [7]. Autism is likely to 
represent a highly complex disorder with multiple etiologies and current treatment approaches to autism are therefore symptomatic [1].

\section{Opioid excess theory and the GFCF diet}

No definitive biomarkers of autism have as yet been identified [7] and several different etiological hypotheses have been proposed. The "opioid excess theory" by Panksepp [8] draws parallels between the disorder's symptoms and the acute behavioral effects of opiates and links the disorder to an increased activity in the endogenous opioid system. Based on this proposal, Reichelt et al. [9, 10] were able to demonstrate a possible nutritional link to autism and hypothesized that certain food proteins such as gluten and casein can be transformed to opioid peptides during digestion. These peptides might be metabolized insufficiently and after accumulation enter the blood circulation through a "leaky gut" due to an increased permeability of the intestinal membrane [11]. After crossing the blood-brain barrier they may act directly upon the central nervous system [12]. As autism is conceptualized as a metabolic disorder according to this hypothesis, an increase in urinary levels of these opioid peptides might be a biomarker of the disorder. A diet low in the above mentioned proteins was hypothesized to normalize the urinary peptide levels (UPL) and hence ameliorate the behavioral symptoms of affected children $[9,12]$.

Studies investigating the urinary profiles of autistic populations were able to show increased levels of certain peptides [9, 10, 13-17]. In addition, some authors reported reductions in these peptide levels and an amelioration of autistic symptoms following the implementation of a gluten-free and casein-free diet (GFCF diet) [13, 15, 16]. These findings have lent some scientific credibility to the etiological account underlying the GFCF diet and advanced the diet's popularity.

\section{GFCF diet - Current Status and Scope of the Review}

Several intervention studies have investigated the effects of a GFCF diet on autistic symptoms. Some of these investigations were summarized in a Cochrane review by Millward et al. [18] who included only two small randomized controlled trials in their evaluation and found mixed results concerning dietary effects. Mulloy et al. [19, 20] concluded on the basis of 14 studies that the findings were contradictory and inconclusive, the methods used were diverse and hardly comparable and the methodological quality of studies was very limited. They also emphasized a possible measurement bias in many studies that relied on subjective ratings of parents not blind to treatment condition. Mulloy et al. [19, 20] therefore suggested the use of GFCF diets only in individuals with food intolerance or allergies related to gluten and/or casein. Since the review's publication, another two dietary intervention studies involving the GFCF diet have been published [21, 22].

The aim of the present review is to analyze the effects of gluten-free and casein-free (GFCF) diets on children with autism on the basis of scientific literature concerning dietary effects on different outcome measures. Guidelines for quality assessment and integration of evidence across methodologies were used [23]. Additional aspects related to the GFCF diet in autism (prevalence of use, possible harmful effects) were also assessed. 


\section{Methods}

A literature search was conducted using PubMed, Medline, ERIC and Google Scholar and including scientific articles published up until December 2013. The search terms used in order to identify relevant articles included combinations of the following: "gluten", "casein", "gliadine", "gluten-free", "casein-free", "GFCF", "diet”, "dietary", "intervention”, "(case) study", "trial”, "autism", "autistic" "autistic disorder", "Asperger”, "autistic spectrum disorder", "ASD”, "child", "adolescent", adult", "complementary and alternative medicine" "CAM" and "survey". Search results were screened for relevant articles involving humans and any kind of GFCF dietary intervention as well as surveys dealing with GFCF as treatment for autism. A total of 18 dietary intervention studies and another 11 survey studies were identified and included. Four studies investigating possible harmful effects of the GFCF diet could be identified. In the present review, biochemical analyses such as the assessment of urinary peptide levels or the analysis of intestinal permeability were not included.

Dietary intervention studies were evaluated regarding the level of evidence (weak, adequate, strong) according to the methodological guidelines by Reichow et al. [23]. These authors published an evaluative method especially suited for the evaluation of intervention studies in autism. This method allows the integration of evidence across different kinds of outcome studies (single case vs. group research studies) based on an evaluation of specified methodological quality indicators thought to be essential for each kind of research design [23].

\section{Results of Prevalence Studies}

In 11 surveys attempting to assess the prevalence of the GFCF diet in autism spectrum disorder (ASD) populations, this diet was one of several treatment options. The studies were conducted to investigate the popularity of complementary and alternative medicine (CAM) treatment in ASD populations. These studies indicated a current use of GFCF diets in 8-32\% of families and a lifetime use in 20-50\% of families [24-35]. These studies show that parents frequently report the use of multiple CAM treatments including dietary treatments. These treatments include dietary supplementation with vitamins or minerals and specific forms of diet (Feingold diet, sugar free, GFCF etc.), of which the GFCF diet appears to be the most prominent [e.g. 24, 27]. Any clinical investigation attempting to elucidate the efficacy of a specific treatment modality should control for the use of these CAM treatments. For example, Green et al. [27] showed that parents report a current use of a mean of seven different treatment modalities (including CAM) for their children. The high number of different treatment options was confirmed by some [30,35] but not all [32] studies and should be assessed more thoroughly using various national and socio-demographic levels. As there are indications that the parents of both more severe and younger cases of ASD use CAM treatments more frequently, it is obvious that scientific investigations need to assess and control for these alternative treatments and their potential effects regarding ASD symptoms.

In regard to effects on ASD symptoms, only a subset of survey studies assessed parental perceptions of GFCF dietary effects [24, 28, 29, 36]. These studies found positive effects reported by 41-69 \% of parents, when categorical answers were required. A recent UK survey study [35] asked parent and expert groups about their experiences and perceptions regarding the use of a variety of treatment options. The parents reported current use of an average of four 
treatment modalities and more than $80 \%$ reported some kind of dietary intervention (GFCF diet in $29 \%$ ) for their child. When asked about the effects of the GFCF diet on various symptom domains, 20-29\% of the parents reported significant improvements (on a dimensional Likerttype answer scale) on the ASD core dimensions. However, marked improvements of their children regarding gastrointestinal symptoms and concentration/attention were reported by $54 \%$ and $42 \%$ of parents, respectively [35]. This finding, i.e. the more pronounced dietary effect on comorbid problems, is supported by a survey by Pennesi and Klein [33] who found that parents reported more positive effects of a GFCF diet when their child showed gastrointestinal symptoms or signs of allergy. This finding suggests that there might be a subset of children with ASD who could benefit from a GFCF diet. This requires further exploration and needs to be validated by clinical observations in addition to parents' reports.

In summary, the above mentioned results show that the GFCF diet is a CAM treatment option used by approximately $25 \%$ of families with children diagnosed with ASD. Furthermore, the diet is perceived by the majority of parents to have positive effects on various aspects of the children's functioning. There are indications that it may not be the core dimensions of autistic symptomatology that are influenced most effectively by the diet. This point deserves further consideration in dietary intervention studies designed for the identification of moderating variables. Future prevalence surveys should be conducted with a stronger focus on comparability of results across studies in order to allow for the analysis of trends in the use of treatment options.

\section{Results of Case Studies}

A total of eight published case studies, including anecdotal case reports and studies using a more or less experimental research design, attempted to establish a causal role of gluten/casein in autism [21, 37-43]. Not a single study was conducted with adequate scientific rigor and the results of these studies can be regarded as weak evidence at best. None of the studies implemented an experimental control meeting the criteria by Reichow et al. [23]. Two studies $[40,43]$ established an adequate measurement baseline for at least some of the measures. All but two studies [37, 38] found evidence of positive dietary effects for at least some of the measures assessed, e.g. physical development, autistic symptomatology or cognitive skills. The two studies providing null results differed from most of the other studies by two aspects, i.e. trial duration and kind of outcome measure. The experimental condition in these studies was implemented no longer than about one week which was short compared to the other studies with observation periods of up to several years. Another difference is the use of different outcome measures, namely behavioral observations and the use of objective coding schemes. The dependent measures were thus assessed by persons less closely related to the children than parents. The two studies with null results were the case studies meeting the largest number of quality indicators within this group of studies ( 6 and 7 out of 12 indicators). Another problem of two case studies using standardized testing procedures $[42,43]$ relates to an inadequate use of test/measurement data, i.e. the calculation of mental age scores from raw data [43] or the use of raw data itself [42] in order to determine treatment progress. This procedure might seem feasible in short-term evaluations of treatment effects or in the adult age range. However, in long-term evaluations and 
in the age ranges covered by the published case studies of GFCF dietary effects (3-12 years of age), every attempt should be made in order to control for time or maturational effects. This could be achieved by using well-standardized and instruments, which allow the calculation of age-sensitive standard scores (e.g. percentile ranks). Another relevant aspect relates to parents as source of information. Each of the 6 studies showing at least some beneficial dietary effects used parents as informants on their children's autistic behavior symptoms. This point deserves further consideration and future case studies should implement observational measures, standardized test procedures and clinician-ratings as complementary measures of dietary effects.

In summary, evidence concerning therapeutic effects of a GFCF diet, as provided by single case studies, is very weak. The studies are hampered by many and mainly basic methodological flaws which do not allow any clear-cut interpretation of their results. While six of the eight identified studies were able to show at least some positive effects of the GFCF diet, two studies using behavioral observations as sole dependent measure were unable to show clear dietary effects [37, 38]. Future case studies of GFCF dietary effects should use a more sophisticated research design, at least by establishing a reliable measure baseline which can be used to evaluate the effects following the diet. This relates to both behavioral observations and the data of standardized developmental testing procedures. Potential dietary effects on these measures (e.g. changes in percentile ranks) should be compared with parental reports of changes in problem behaviors and other symptoms. Parental ratings may be complemented by judgments of clinicians in order to strengthen the assessment. Inter-observer agreement is another important scientific criterion [23] when attempting to find evidence of the effects of the GFCF diet. It should be noted, that the observational studies [37, 38, 40] were the only ones using this kind of quality evaluation. All the observational studies were conducted in institutional settings and the ecological validity of the results remains therefore to be established.

\section{Results of Group Studies}

A total of 10 group studies were found in the published literature. One of these studies [44] can be dismissed as unscientific due to unclear definitions of improvement and descriptions of information sources. Another six group studies [13, 15, 16, 45-50] were conducted without adequate scientific rigor and could therefore provide only weak evidence concerning potential effects of a GFCF dietary modulation. With the exception of one study [45, 46], all of these studies found at least some positive effects of a GFCF dietary modulation concerning autistic symptoms, cognitive and language skills, motor problems or gastrointestinal symptoms. Three studies were conducted with more scientific rigor and provided an adequate level of scientific evidence [22, 51-54]. Two of these studies $[22,51]$ showed null results regarding dietary effects, while the remaining study [54] provided mixed evidence for positive dietary effects on several autistic features and other behavioral symptoms.

A problematic aspect of the group studies was the inadequate operationalization of a comparison condition, i.e. (1) the use of no control procedures at all [13, 15, 16, 44], (2) the use of control groups for only parts of the investigated aspects or subsets of the sample [48] or (3) the neglect of other relevant variables such as the control for additional treatments [22, 47, 49, $51,54]$. Only two studies involving behavioral observations formally assessed interobserver 
agreement [22, 51], while another two studies correlated different measures in order to investigate the validity of study results [13, 48]. Only the three studies of adequate report strength did try to ensure blindness of raters at least for some of the dependent measures [22, 51, 54]. Only four of the studies explicitly stated control procedures to ensure the fidelity of diet implementation throughout the study period [15, 16, 22, 51, 54], two of these studies had the shortest trial duration of all the group studies ( $\sim 3$ months). Some studies did not even report the adequate use of statistical tests, either using none [44], using inadequate tests [13] or not presenting sufficient information as to the adequate use of the tests [46, 48, 51, 54]. Another problem was the use of parental ratings for the assessment of dietary effects.

\section{Summary of Intervention Study Results}

The evaluation of GFCF dietary trials is complicated by various methodological flaws in the majority of the published reports. More sophisticated trials with single case or group research designs provided either mixed or null results regarding dietary effects [22, 37, 38, 51, 54]. These findings might lead to the rejection of the GFCF diet in the treatment of autism. However, the diet durations in four of these studies were among the shortest of the published studies (from 4 days to 3 months) and these methodological differences might account for the results. Almost all of the studies with trial durations of 12 months or longer found some indications of positive developmental change in the dependent measures assessed. However, most of these "positive" studies did not control for alternative explanations such as the effects of additional treatments, maturational effects etc. Evidence-based practice according to the guidelines of Reichow et al. [23] requires at least three independent single case studies or two independent group research studies conducted with at least adequate report strength and each showing the effectiveness of the respective treatment. As none of the single case studies showed adequate report strength and only one of the three group studies with adequate report strength showed some positive (though mixed) results regarding GFCF dietary effects, the diet itself cannot even be judged as promising according to these guidelines.

In summary, the evidence of the GFCF diet's effectiveness in the treatment of autism is too sparse to draw any firm conclusion. Future studies need to be performed with more methodological rigor and be of longer duration in order to be judged as providing adequate or even strong scientific evidence. Furthermore, outcome measures should not be solely based on parental ratings, but include clinical expert ratings as well as naturalistic behavioral observations.

\section{Risk Studies of the GFCF Diet}

The studies of potential harmful effects of a GFCF diet in children with autism were mainly related to one of two aspects, i.e. nutritional adequacy [25, 55, 56] or physical development [57]. Three studies related to nutritional adequacy investigated possible deficiencies of children on restriction diets as compared to healthy control children or children with autism on unrestricted diets. Two of these studies tried to estimate adequacy from dietary records documented by parents and did not find evidence for any more nutritional deficiencies as in respective comparison groups $[25,56]$. The third study found deficiencies in plasma-derived levels of essential amino acids including important neurotransmitter precursors such as tyrosine and 
tryptophan [55]. A study by Hediger et al. (2008) [57] was concerned with physical development and compared the bone cortical thickness of children with autism on a casein-free diet (with a resultant low intake of calcium) with those on unrestricted diets and with reference values. These authors found that the children with autism showed a reduction in bone cortical thickness; the reduction was significantly more pronounced in the group on a casein-free diet [57]. These aspects should be considered more thoroughly and on a routine basis in future studies of GFCF dietary effects.

\section{Concluding Remarks and Future Directions}

The scientific evaluation of long-term and high-effort dietary interventions such as the GFCF diet is no easy-to-manage task. There are many methodological problems which have to be met by adequate research designs which might not be available due to practical or financial reasons. Based on the above mentioned methodological shortcomings of existing studies and conceptual issues related to the GFCF diet, recommendations for future dietary studies include the implementation of adequate control procedures for single case or group research studies, the use of standardized assessment instruments in intervention studies in autism and the choice of adequate trial durations and of a wider range of measures.

The scientific basis regarding the efficacy of the GFCF diet in the treatment of autism is very sparse and cannot even be judged as promising. Despite the diet's popularity as a supplementary treatment, its widespread use (according to the prevalence studies) and the positive views of parents regarding its effects, most of the more rigorous scientific evaluations failed to confirm these observations. There is a large number of seriously flawed studies and the few methodologically acceptable studies conducted to date do not allow firm conclusions concerning the diet's efficacy. The establishment of a clear link between the diet's implementation and positive effects on autistic symptoms would be a major step in the evaluation of the "opioid excess theory". A scientifically sound evaluation of this theory is currently impossible on the basis of published research.

In recent years, other studies conducted within the framework of the "opioid excess theory" failed to confirm some of the theory's major predictions, e.g. the detection of heightened urinary (opioid) peptide levels $[48,51,58-60]$. These observations also weaken the underlying rationale for the recommendation and use of the GFCF diet as a direct and compensatory treatment of the hypothesized etiology of autism. Nevertheless, future dietary studies in this area should implement methodologically sound designs in order to establish more convincing evidence regarding dietary effects.

Although the dietary studies performed so far do not seem to confirm the predictions of the "opioid excess theory" and the conceptualization of autism as a metabolic disorder, the case of nutrition in autism should not be closed preemptively. As there is increasing evidence of possible links between gut anomalies and the autistic brain [61], which also point to the importance of immunological factors and their role in the frequently observed gastrointestinal disturbances in autistic children, the consideration of gluten/casein and other dietary factors should not be rejected prematurely in autism research. The conceptualization of autism as an immunological disorder could explain multiple environmentally-mediated pathways leading to autistic 
symptoms. Within such a theoretical model, gluten/casein and other food-derived proteins might play a role in triggering allergic responses, which might have some influence on brain development and function by exerting direct influence upon neuronal function [see 61]. Although the literature regarding possible links between autism and allergic reactions to gluten/casein is promising [62, 63, 64], there is a need for more scientific studies investigating the role of nutrition in the etiology and treatment of autism.

Abbreviations: autism spectrum disorder (ASD), complementary and alternative medicine (CAM), gluten-free and casein-free diet (GFCF diet), urinary peptide levels (UPL)

Competing interests: The authors have no financial interests or conflicts of interest.

Authors' Contributions: All authors contributed to this study.

\section{REFERENCES:}

1. Levy SE, Mandell DS, Schultz RT: Autism. Lancet 2009, 374:1627-1638.

2. American Psychiatric Association: Diagnostic and statistical manual of mental disorders: DSM-5. Washington, DC \{[u.a.]: American Psychiatric Publ.; 2013.

3. Fombonne E: Epidemiology of pervasive developmental disorders. Pediatr Res 2009, 65:591-598.

4. Herbert MR: Contributions of the environment and environmentally vulnerable physiology to autism spectrum disorders. Curr Opin Neurol 2010, 23:103-110.

5. Curtis LT, Patel K: Nutritional and environmental approaches to preventing and treating autism and attention deficit hyperactivity disorder (ADHD): a review. Journal of alternative and complementary medicine (New York, N Y ) 2008, 14:79-85.

6. Parellada M, Penzol MJ, Pina L, Moreno C, Gonzalez-Vioque E, Zalsman G, Arango C: The neurobiology of autism spectrum disorders. Eur Psychiatry 2014, 29:11-19.

7. Walsh P, Elsabbagh M, Bolton P, Singh I: In search of biomarkers for autism: scientific, social and ethical challenges. Nat Rev Neurosci 2011, 12:603-612.

8. Panksepp J: A neurochemical theory of autism. Trends Neurosci 1979, 2:174-177.

9. Reichelt KL, Knivsberg A-M, Lind G, Nødland M: Probable etiology and possible treatment of childhood autism. Brain Dysfunction 1991, 4:308-319.

10. Reichelt KL, Hole K, Hamberger A, Saelid G, Edminson PD, Braestrup CB, Lingjaerde O, Ledaal P, Orbeck H: Biologically active peptide-containing fractions in schizophrenia and childhood autism. Adv Biochem Psychopharmacol 1981, 28:627-643.

11. D'Eufemia P, Celli M, Finocchiaro R, Pacifico L, Viozzi L, Zaccagnini M, Cardi E, Giardini O: Abnormal intestinal permeability in children with autism. Acta Paediatr 1996, 85:1076-1079. 
12. Shattock P, Whiteley P: Biochemical aspects in autism spectrum disorders: updating the opioid-excess theory and presenting new opportunities for biomedical intervention. Expert Opin Ther Targets 2002, 6:175-183.

13. Cade R, Privette M, Fregly M, Rowland N, Sun Z, Zele V, Wagemaker H, Edelstein C: Autism and Schizophrenia: Intestinal Disorders Nutr Neurosci 2000, 3:57-72.

14. Israngkun PP, Newman HA, Patel ST, Duruibe VA, Abou-Issa H: Potential biochemical markers for infantile autism. Neurochem Pathol 1986, 5:51-70.

15. Knivsberg AM, Reichelt KL, Nødland M, Høien T: Autistic Syndromes and Diet: a follow-up study. Journal of Curriculum Studies 1995, 39:223-236.

16. Knivsberg A-M, Wiig K, Lind G, Nødland M: Dietary intervention in autistic syndromes. Brain Dysfunction 1990.

17. Reichelt KL, Saelid G, Lindback T, Boler JB: Childhood autism: a complex disorder. Biol Psychiatry 1986, 21:1279-1290.

18. Millward C, Ferriter M, Calver S, Connell-Jones G: Gluten- and casein-free diets for autistic spectrum disorder. Cochrane Database Syst Rev 2008:CD003498.

19. Mulloy A, Lang R, O’Reilly M, Sigafoos J, Lancioni G, Rispoli M: Gluten-free and casein-free diets in the treatment of autism spectrum disorders: a systematic review. Res Autism Spectr Disord 2010, 4:328-339.

20. Mulloy A, Lang R, O’Reilly M, Sigafoos J, Lancioni G, Rispoli M: Addendum to "gluten-free and casein-free diets in treatment of autism spectrum disorders: A systematic review". Res Autism Spectr Disord 2011, 5:86-88.

21. Herbert MR, Buckley JA: Autism and dietary therapy: case report and review of the literature. J Child Neurol 2013, 28:975-982.

22. Johnson CR, Handen BL, Zimmer M, Sacco K, Turner K: Effects of gluten free/casein free diet in young children with autism: a pilot study. J Dev Phys Disabil 2011, 23:213225.

23. Reichow B, Volkmar FR, Cicchetti DV: Development of the evaluative method for evaluating and determining evidence-based practices in autism. J Autism Dev Disord 2008, 38:1311-1319.

24. Smith T, Antolovich M: Parental perceptions of supplemental interventions received by young children with autism in intensive behavior analytic treatment. Behav Interv 2000, 15:83-97.

25. Cornish E: Gluten and casein free diets in autism: a study of the effects on food choice and nutrition. J Hum Nutr Diet 2002, 15:261-269.

26. Levy SE, Mandell DS, Merhar S, Ittenbach RF, Pinto-Martin JA: Use of complementary and alternative medicine among children recently diagnosed with autistic spectrum disorder. J Dev Behav Pediatr 2003, 24:418-423.

27. Green VA, Pituch KA, Itchon J, Choi A, O'Reilly M, Sigafoos J: Internet survey of treatments used by parents of children with autism. Res Dev Disabil 2006, 27:70-84.

28. Hanson E, Kalish LA, Bunce E, Curtis C, McDaniel S, Ware J, Petry J: Use of complementary and alternative medicine among children diagnosed with autism spectrum disorder. J Autism Dev Disord 2007, 37:628-636. 
29. Goin-Kochel RP, Mackintosh VH, Myers BJ: Parental reports on the efficacy of treatments and therapies for their children with autism spectrum disorders. Res Autism Spectr Disord 2009, 3:528-537.

30. Goin-Kochel RP, Myers BJ, Mackintosh VH: Parental reports on the use of treatments and therapies for children with autism spectrum disorders. Res Autism Spectr Disord 2007, 1:195-209.

31. Carter M, Roberts J, Williams K, Evans D, Parmenter T, Silove N, Clark T, Warren A: Interventions used with an Australian sample of preschool children with autism spectrum disorders. Res Autism Spectr Disord 2011, 5:1033-1041.

32. Bowker A, D'Angelo NM, Hicks R, Wells K: Treatments for autism: parental choices and perceptions of change. J Autism Dev Disord 2011, 41:1373-1382.

33. Pennesi CM, Klein LC: Effectiveness of the gluten-free, casein-free diet for children diagnosed with autism spectrum disorder: based on parental report. Nutr Neurosci 2012, 15:85-91.

34. Perrin JM, Coury DL, Hyman SL, Cole L, Reynolds AM, Clemons T: Complementary and alternative medicine use in a large pediatric autism sample. Pediatrics 2012, 130 Suppl 2:S77-82.

35. Winburn E, Charlton J, McConachie H, McColl E, Parr J, O'Hare A, Baird G, Gringras P, Wilson DC, Adamson A, Adams S, Le Couteur A: Parents' and Child Health Professionals' Attitudes Towards Dietary Interventions for Children with Autism Spectrum Disorders. J Autism Dev Disord 2013.

36. Adams JB. Summary of Dietary, Nutritional, and Medical Treatments for Autism - based on over 150 published research studies http://ariconference.com/enews/treatment.pdf: Autism Research Institute; 2013.

37. Irvin DS: Using analog assessment procedures for determining the effects of a gluten-free and casein-free diet on rate of problem behaviors for an adolescent with autism. Behav Interv 2006, 21:281-286.

38. Bird BL, Russo DC, Cataldo MF: Considerations in the analysis and treatment of dietary effects on behavior: a case study. J Autism Child Schizophr 1977, 7:373-382.

39. Fields M, Fields P: The relationship between problem behavior and food allergies: one family's story. J Autism Child Schizophr 1976, 6:75.

40. O'Banion D, Armstrong B, Cummings RA, Stange J: Disruptive behavior: a dietary approach. J Autism Child Schizophr 1978, 8:325-337.

41. Adams L, Conn S: Nutrition and its relationship to autism. Focus Autism Other Dev Disabl 1997, 12:53-58.

42. Knivsberg AM, Reichelt KL, Nødland M: Dietary Intervention for a Seven Year Old Girl with Autistic Behaviour. Nutr Neurosci 1999, 2:435-439.

43. Hsu CL, Lin CY, Chen CL, Wang CM, Wong MK: The effects of a gluten and caseinfree diet in children with autism: a case report. Chang Gung Med J 2009, 32:459-465.

44. Jyonouchi $\mathrm{H}$, Sun S, Itokazu N: Innate immunity associated with inflammatory responses and cytokine production against common dietary proteins in patients with autism spectrum disorder. Neuropsychobiology 2002, 46:76-84. 
45. Gemmell M, Chambliss C: Effects of a gluten-free diet on rate of achievement in autistic children in an applied behavioural anaylsis program. Research Report: Urisnus College [ED406761]; 1997.

46. Pontino JL, Schaal K, Chambliss C: Effects of a gluten-free diet on rate of achievement in autistic children in an applied behavioural anaylsis program: summary analysis. Research Report: Ursinus College [ED413689]; 1998.

47. Lucarelli S, Frediani T, Zingoni AM, Ferruzzi F, Giardini O, Quintieri F, Barbato M, D'Eufemia P, Cardi E: Food allergy and infantile autism. Panminerva Med 1995, 37:137141.

48. Whiteley P, Rodgers J, Savery D, Shattock P: A gluten-free diet as an intervention for autism and associated spectrum disorders: preliminary findings. Autism 1999, 3:45-65.

49. Knivsberg AM, Reichelt KL, Høien T, Nødland M: A randomised, controlled study of dietary intervention in autistic syndromes. Nutr Neurosci 2002, 5:251-261.

50. Knivsberg A-M, Reichelt K-L, Høien T, Nødland M: Effect of a dietary intervention on autistic behavior. Focus Autism Other Dev Disabl 2003, 18:248-257.

51. Elder JH, Shankar M, Shuster J, Theriaque D, Burns S, Sherrill L: The gluten-free, casein-free diet in autism: results of a preliminary double blind clinical trial. J Autism Dev Disord 2006, 36:413-420.

52. Seung H, Rogalski Y, Shankar M, Elder J: The gluten-and casein-free diet and autism: Communication outcomes from a preliminary double-blind clinical trial. J Med Speech Lang Pathol 2007, 15:337-345.

53. Pedersen L, Parlar S, Kvist K, Whiteley P, Shattock P: Data mining the ScanBrit study of a gluten- and casein-free dietary intervention for children with autism spectrum disorders: Behavioural and psychometric measures of dietary response. Nutr Neurosci 2013:[Epub ahead of print].

54. Whiteley P, Haracopos D, Knivsberg AM, Reichelt KL, Parlar S, Jacobsen J, Seim A, Pedersen L, Schondel M, Shattock P: The ScanBrit randomised, controlled, single-blind study of a gluten- and casein-free dietary intervention for children with autism spectrum disorders. Nutr Neurosci 2010, 13:87-100.

55. Arnold GL, Hyman SL, Mooney RA, Kirby RS: Plasma amino acids profiles in children with autism: potential risk of nutritional deficiencies. J Autism Dev Disord 2003, 33:449454.

56. Hyman SL, Stewart PA, Schmidt B, Cain U, Lemcke N, Foley JT, Peck R, Clemons T, Reynolds A, Johnson C, Handen B, James SJ, Courtney PM, Molloy C, Ng PK: Nutrient intake from food in children with autism. Pediatrics 2012, 130(Suppl 2):145-153.

57. Hediger ML, England LJ, Molloy CA, Yu KF, Manning-Courtney P, Mills JL: Reduced bone cortical thickness in boys with autism or autism spectrum disorder. J Autism Dev Disord 2008, 38:848-856.

58. Cass H, Gringras P, March J, McKendrick I, O'Hare AE, Owen L, Pollin C: Absence of urinary opioid peptides in children with autism. Arch Dis Child 2008, 93:745-750.

59. Dettmer K, Hanna D, Whetstone P, Hansen R, Hammock BD: Autism and urinary exogenous neuropeptides: development of an on-line SPE-HPLC-tandem mass 
spectrometry method to test the Opioid Excess Theory. Anal Bioanal Chem 2007, 388:1643-1651.

60. Hunter LC, O'Hare A, Herron WJ, Fisher LA, Jones GE: Opioid peptides and dipeptidyl peptidase in autism. Dev Med Child Neurol 2003, 45:121-128.

61. de Theije CG, Wu J, da Silva SL, Kamphuis PJ, Garssen J, Korte SM, Kraneveld AD: Pathways underlying the gut-to-brain connection in autism spectrum disorders as future targets for disease management. Eur J Pharmacol 2011, 668(Suppl 1):70-80.

62. de Magistris L, Picardi A, Siniscalco D, Riccio MP, Sapone A, Cariello R, Abbadessa S, Medici N, Lammers KM, Schiraldi C, Iardino P, Marotta R, Tolone C, Fasano A, Pascotto A, Bravaccio C: Antibodies against food antigens in patients with autistic spectrum disorders. Biomed Res Int 2013, 2013:729349.

63. Lau NM, Green PH, Taylor AK, Hellberg D, Ajamian M, Tan CZ, Kosofsky BE, Higgins JJ, Rajadhyaksha AM, Alaedini A: Markers of Celiac Disease and Gluten Sensitivity in Children with Autism. PLoS One 2013, 8:e66155.

64. Vojdani A, O'Bryan T, Green JA, McCandless J, Woeller KN, Vojdani E, Nourian AA, Cooper EL: Immune response to dietary proteins, gliadin and cerebellar peptides in children with autism. Nutr Neurosci 2004, 7:151-161. 